\title{
ARTICLE
}

\section{Prediction and estimation of dose around Pressure Containment Vessel containing BWR plant fuel debris}

\author{
Hideo Nakano*, Hiroyuki Handa and Toshihisa Tsukiyama \\ Hitachi-GE Nuclear Energy, Ltd., 3-1-1, Saiwai-cho, Hitachi-shi, 317-0073, Japan
}

\begin{abstract}
As part of decommissioning efforts of the Fukushima Daiichi nuclear power station, removing the fuel debris from the Pressure Containment Vessel (PCV) and its preparation tasks are planned. In order to conduct efficiently above tasks, it is important to predict the dose rate in the work areas for the radiation workers. However, the locations of fuel debris have not necessarily been confirmed and the radiation measurement data of inside the PCV are not sufficiently obtained in the present. Besides the effect of dose rate due to the lump debris, the PCV area is supposedly considered a high dose rate due to the contaminated radionuclide in the stagnant water and on the surface inside the PCV. In order to evaluate dose rate due to radiation emitted from the fuel debris and other radiation sources inside the PCV, we made calculations using ANISN and DORT.
\end{abstract}

Keywords: fuel debris; PCV; ANISN; DORT; dose rate

\section{Introduction}

In the massive nuclear accident at the Fukushima Daiichi nuclear power station, the reactors for Units 1,2, and 3 were shut down automatically after the earthquake, but the functions for cooling the decay heat of the fuel were lost as the tsunami disabled all power supplies. As a result, the core fuel that melted at high temperatures became fuel debris of indefinite shape.

The locations of fuel debris have not necessarily been confirmed, but most of the fuel debris was assumed to fall into the lower part of the Reactor Pressure Vessel (RPV) and some debris reached the bottom part of the Pressure Containment Vessel (PCV). Although the dose rate in the PCV area is supposedly considered very high due to the fuel debris, the fuel debris must be removed as part of decommissioning efforts.

Above work faces many technical issues in order to deal with the conditions of a high dose rate. Radiation protection is important for the safety of nuclear power plants; therefore, the exposure dose should be kept as low as reasonably achievable for radiation workers. This entails predicting the dose rate in the work area.

In this work, we conducted analysis using calculation codes to evaluate radiation dose rate around the PCV due to radiation emitted from various sources including fuel debris.

\section{Overview of calculation}

As shown in Figure 1, the reactors for Units 1, 2, and 3 are equipped with the Mark-I PCV, and the calculating objects were taken as Mark-1 PCVs. This work utilized a one-dimensional discrete ordinates transport code (ANISN) [1] and a two-dimensional discrete ordinates transport code (DORT) [2] for estimating dose rate. In DORT calculations, we evaluated the dose rate around the PCV due to the radiation emitted from various radiation sources, including fuel debris. The ANISN calculations were used to extrapolate the DORT calculations to the decay time condition of debris radioactivity.

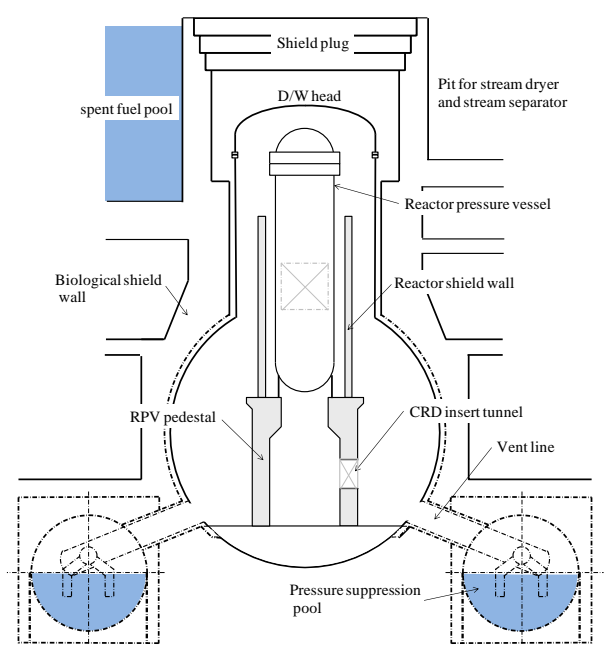

Figure 1. Schematic of MARK-1 PCV of BWR.

\footnotetext{
*Corresponding author. Email: hideo.nakano.ne@hitachi.com
} 


\section{Calculation conditions}

\subsection{Radiation sources}

The gamma ray and neutron sources emitted from the fuel debris were calculated using the ORIGEN2 [3] computer code for calculating the buildup, decay, and processing of radioactive materials.

Table 1 lists the source conditions of the fuel debris. The specific power and burnup were set somewhat conservatively as compared to the expected average values, as this work was intended to tentatively evaluate the dose rate.

The neutron energy spectrum must be set as an arbitrary energy spectrum because it is not output in the ORIGEN2 code. In this calculation, the fission spectrum of $\mathrm{Pu}-239$ was selected for the following reasons:

(1) Most neutrons in the fuel are spontaneous fission neutrons due to ORIGEN2 output.

(2) The fission spectrum of Pu-239 is more conservative than the fission spectra of other isotopes in evaluating dose rate.

In DORT calculations, radiation sources are assumed to be contaminated radionuclides in stagnant water and on the surface of inside the PCV, and to be radioactivated equipments of core internals (see Table 2), in addition to the fuel debris.

Table 1. Source conditions of fuel debris.

\begin{tabular}{c|l|l}
\hline No. & Item & Condition \\
\hline 1 & Fuel assembly type & $9 \times 9$ fuel assembly (Type A) \\
\hline 2 & Specific power & $34.48 \mathrm{MW} / \mathrm{t}$ \\
\hline 3 & Burnup & $45 \mathrm{GWD} / \mathrm{t}$ \\
\hline 4 & Decay time & 1,3 and $10 \mathrm{y}$ \\
\hline 5 & Uranium mass & $6.8 \times 10^{4} \mathrm{~kg}$ \\
\hline
\end{tabular}

Table 2. Source conditions except for fuel debris.

\begin{tabular}{|c|c|c|c|c|}
\hline \multicolumn{2}{|c|}{ Radiation source } & Nuclide & $\begin{array}{c}\text { Density of } \\
\text { radioactivity } \\
\left(\mathrm{Bq} / \mathrm{cm}^{3}\right)\end{array}$ & Basis \\
\hline \multirow{2}{*}{\multicolumn{2}{|c|}{$\begin{array}{l}\text { Stagnant water at the } \\
\text { basement floor of reactor } \\
\text { building }\end{array}$}} & Cs-134 & $2.5 \times 10^{6}$ & \multirow{2}{*}{$\begin{array}{l}\text { Based on the measurements of radioactive } \\
\text { concentration of gamma-ray nuclides in } \\
\text { the stagnant water on the basement floor } \\
\text { of reactor building on May } 27 \text { th, } 2011[4] \text {, } \\
\text { the density of radioactivity of the stagnant } \\
\text { water was set. }\end{array}$} \\
\hline & & Cs-137 & $2.9 \times 10^{6}$ & \\
\hline \multirow{3}{*}{$\begin{array}{l}\text { Core } \\
\text { internals }\end{array}$} & Top fuel guide & \multirow{3}{*}{ Сo-60 } & $4.7 \times 10^{9}$ & \multirow{3}{*}{$\begin{array}{l}\text { Based on the measurements of gamma } \\
\text { dose rate on the surface of equipments in a } \\
\text { similar type of nuclear power plant [5], the } \\
\text { density of radioactivity of the activated } \\
\text { equipments were set. }\end{array}$} \\
\hline & Upper core shroud & & $1.6 \times 10^{10}$ & \\
\hline & Lower core shroud & & $8.8 \times 10^{7}$ & \\
\hline \multirow{2}{*}{\multicolumn{2}{|c|}{ Surface of inside the PCV }} & Cs-134 & $2.4 \times 10^{7}$ & \multirow{2}{*}{$\begin{array}{l}\text { Based on the containment atmospheric } \\
\text { radiation monitors measured value on } \\
\text { October 5th, 2011[4], the density of } \\
\text { radioactivity on the surface inside the PCV }\end{array}$} \\
\hline & & Cs-137 & $2.7 \times 10^{7}$ & \\
\hline
\end{tabular}

\subsection{Calculation model}

DORT calculations are based on a model using R-Z cylinder geometry. Figure 2 shows an example of the calculation model. Part of CRD insert tunnel and vent pipes are modeled as opening along the circumference direction of the cylinder model.

As for core internals, the core shroud and top fuel guide were modeled as radiation sources. The top fuel guide was modeled as a mixing area of stainless steel and air, and used the mixture density obtained by the volume and weight of the equipment.

Since the locations of fuel debris are not necessarily confirmed, DORT calculations assume the following:

(1) All fuel debris remains at the bottom of the RPV.

(2) Half of the fuel debris remains at the bottom of the RPV. The rest of the debris dropped inside the RPV pedestal in the lower drywell space.

(3) All fuel debris dropped inside the RPV pedestal in the lower drywell space.

In the conditions above, there is no water in the lower drywell.

By assuming that a radiation detector is inserted from the PCV penetration hole for investigating inside the $\mathrm{PCV}$, we also conducted DORT calculations under conditions where the lower drywell is filled with water (at a height of about $3.4 \mathrm{~m}$ above the floor).

Figure 3 shows the calculation model used in ANISN calculations.

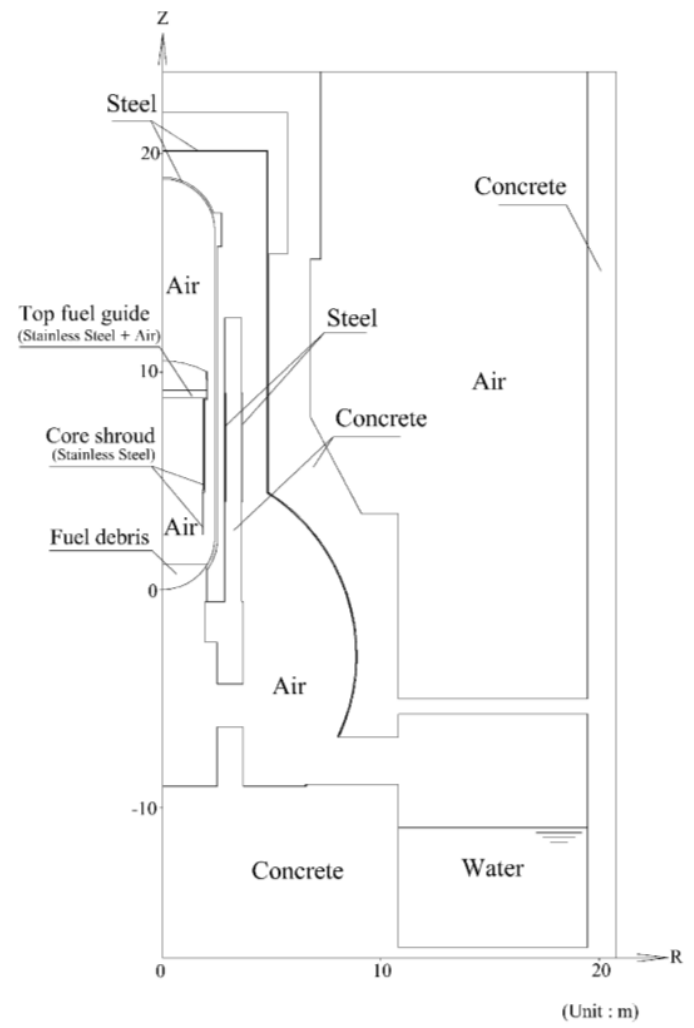

Figure 2. Example of calculation model for DORT.

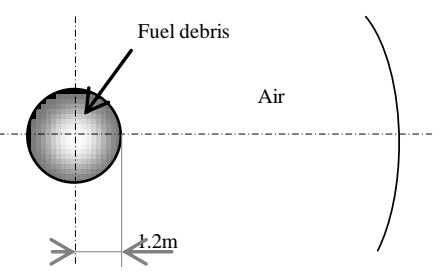

Figure 3. Calculation model for ANISN. 


\subsection{Cross-section library}

As for the multi-group, cross-section library data for ANISN and DORT, the MATXSLIB-J33 [6] library (neutron 175 group energy and gamma ray 42 group energy, P5 Legendre expansion) based on JENDL-3.3 [7] was used. Self-shielding correction was made by using the TRANSX 2.15 code [8].

\subsection{Dose conversion coefficient}

The dose conversion coefficient converted from the fluencies of photons and neutrons into the dose, as based on ICRP publication 74 [9], was used.

\section{Results and discussion}

Figure 4 shows the correlation curve between the decay time after the reactor shutdown and dose rate on the fuel debris surface. Gamma rays are the dominant radiation emitted from the fuel debris. There is about a one-digit difference between the gamma ray dose rate of one-year decay and that of ten-year decay.

Figure 5 shows the dose rate maps around the PCV due to the radiation emitted from various sources, including one-year cooling fuel debris. The difference between the dose rates depend on the position of debris.

If the fuel debris are falling inside RPV pedestal where water is not exist, amount of the radiation streaming through the CRD insert tunnel are large. However, radiation doses emitted from debris are almost as same as rates caused by contaminated radiation on the inner surface of the PCV. The biological shield walls have thickness enough to attenuate radiation dose from the inner surface of the PCV. Therefore radiation doses in the reactor building outside PCV, except for outside the penetration holes, are considered as the effect of contamination of the outside of biological shield walls than PCV inside.

If the lower drywell is not filled with water, the locations of debris can be roughly confirmed based on the distribution of dose rate in the lower drywell space. However, the lower drywell will supposedly be partially filled with water during radiation measurement in the PCV. In above conditions, it is difficult to identify the locations of debris based on the distribution of dose rate in the lower drywell space because radiation doses are attenuated by water shield.

For this reason, gamma-ray detectors must approach the vicinity of the fuel debris, that is, it must be inserted into stagnant water at the bottom of the PCV. By cleaning up the stagnant water containing the fuel debris in the future, it is assumed that the radioactive concentration in the water is lower. For this reason, gamma ray detector is more likely to detect the gamma rays emitted from debris in the water. In addition, it is considered useful to measure the gamma ray as well as neutrons emitted from debris in identifying the locations of fuel debris. For example, we recommend to use a neutron probe which is able to withstand high temperatures such as in fuel debris.

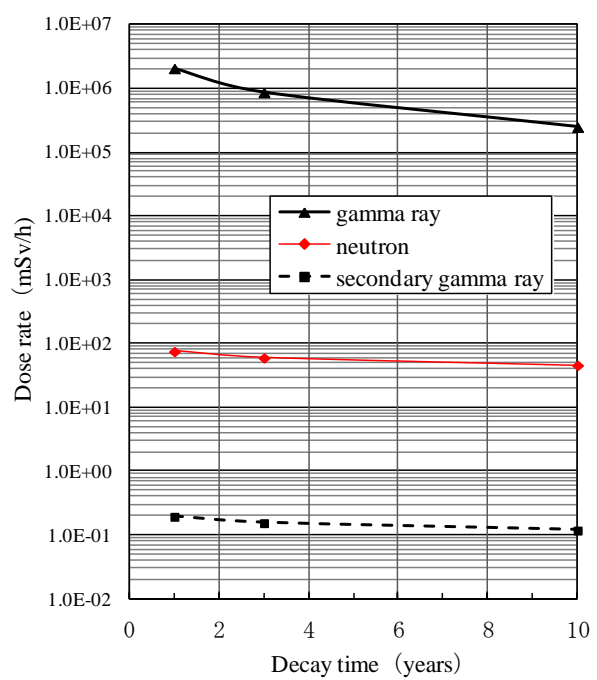

Figure 4. Correlation curves between the decay time and dose rate on the fuel debris surface.

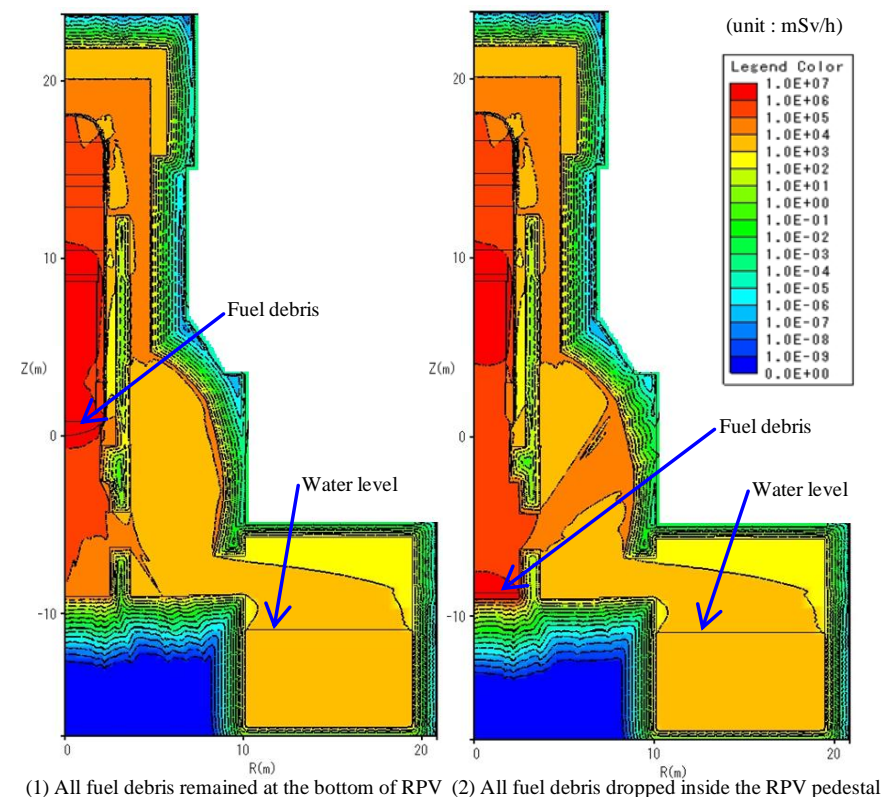

(1) All fuel debris remained at the bottom of RPV (2) All fuel debris dropped inside the RPV pedestal
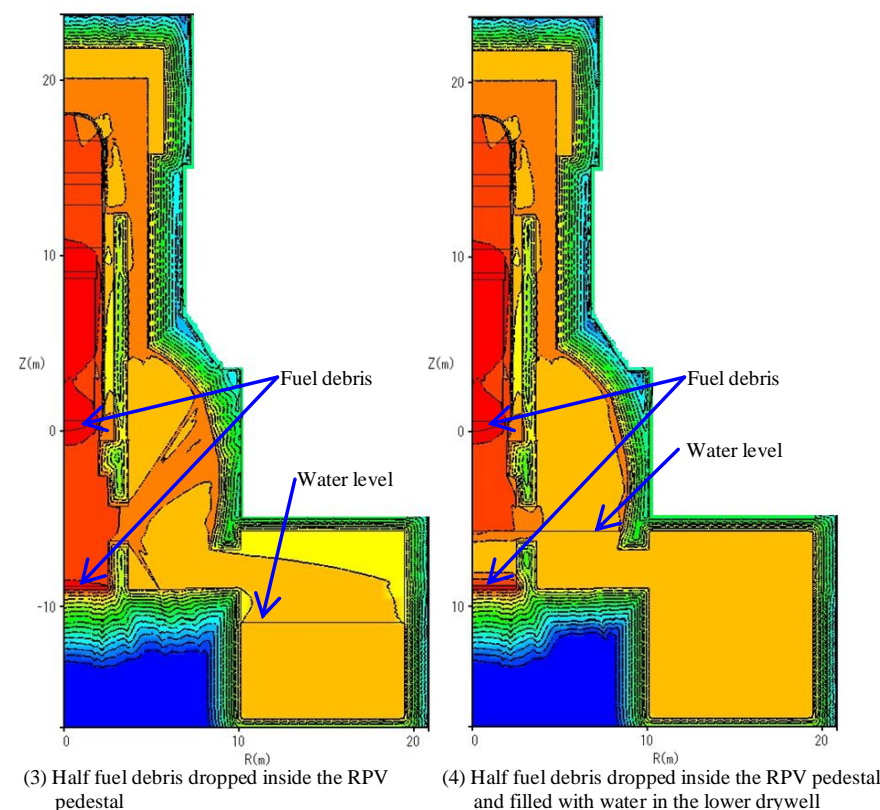
pedestal

Figure 5. Dose rate maps around the PCV. 


\section{Conclusion}

According to this calculation, the following can be concluded.

(1) The locations of fuel debris can be roughly confirmed based on the distribution of doses in the lower drywell space when the lower drywell is not filled with water.

(2) In order to determine the locations of fuel debris, gamma-ray detectors must be approach the vicinity of the fuel debris when the lower drywell is filled with water on some level.

(3) The locations of fuel debris can be determined accurately by combining the radiation measurements to be obtained in stages inside the PCV with the calculations of doses.

\section{References}

[1] W. W. Engle, Jr., A User's Manual for ANISN, A One Dimensional Discrete Ordinates Transport Code with Anisotropic Scattering, K-1693 (1967).
[2] Oak Ridge National Laboratory, DOORS3.2a: One, Two- and Three-Dimensional Discrete Ordinates Neutron/Photon Transport Code System, RSICC Computer Code Collection CCC-650, (2003).

[3] A. G. Croff, A User's Manual for the ORIGEN2 Computer Code, ORNL/TM-7175, Oak Ridge National Laboratory, (1980).

[4] http://www.tepco.co.jp

[5] Hitachi Ltd., Private Correspondence.

[6] K. Kosako, N. Yamano, T. Fukahori, K. Shibata and A. Hasegawa, The Libraries FSXLIB and MATXSLIB Based on JENDL-3.3, JAERI-Data/Code 2003-011 (2003).

[7] K. Shibata, et al, Japanese evaluated nuclear data library version 3 revision-3, JENDL-3.3, J. Nucl. Sci. Technol. 39, (2002), p.1125.

[8] R. E. MacFarlane, TRANSX 2, A Code for Interfacing MATXS Cross-section Libraries to Nuclear Transport Codes, LA-12312-MS (1992).

[9] ICRP, Conversion Coefficients for use in Radiological Protection against External Radiation, Publication 74, (1995). 